\title{
Influência do Tipo de Ponteira Condutora de Luz na Microdureza de uma Resina Composta
}

\author{
Máx Dobrovolski, Priscilla do Monte R. Busato, Márcio J. Mendonça, \\ Virginia Bosquirolli, Rosana A. Santos, Veridiana Camilotti \\ Departamento de Odontologia, Dentística Restauradora, UNIOESTE
}

\begin{abstract}
Resumo: O objetivo desta pesquisa foi avaliar a influência do tipo de ponteira condutora de luz na microdureza de uma resina composta micro-híbrida. Foram confeccionados 14 corpos de prova da resina composta Opallis (FGM) com dimensões: $5 \times 2$ mm, divididos em dois grupos de acordo com a ponteira condutora de luz do aparelho fotoativador de lâmpada halógena Optilight Plus - GNATUS/300 mW.cm ${ }^{-2}$. GI - ponteira condutora de luz de fibra óptica; GII - ponteira condutora de luz de polímero. Após 24 horas, as medidas de microdureza foram efetuadas com um microdurômetro HMV 2000 (Shimadzu Japão). Cinco penetrações foram efetuadas em cada superfície (topo e base) totalizando 10 penetrações para cada corpo de prova. A análise estatística dos resultados realizada por meio do teste de ANOVA não apresentou diferenças significativas entre os tipos de ponta condutora de luz nas superfícies avaliadas. A análise estatística demonstrou diferença significativa nos valores médios de microdureza superficial entre as superfícies de topo e de base, para ambas as ponteiras. Com base nos resultados obtidos, foi possível concluir que as ponteiras de luz não interferem na microdureza da resina composta, e que ambas apresentaram diferenças estatisticamente significativas nos valores de microdureza das superfícies topo e base.
\end{abstract}

Palavras-chave: Resinas compostas, microdureza e fotopolimerização.

\section{Influence of the Different Light-Curing TIPS in the Microhardness of a Composite Resin}

\begin{abstract}
The aim of this study is to evaluate the influence of the light-curing tips on the microhardness of a micro-hybrid composite resin. Fourteen samples of Opallis (FGM) composite resin with $5 \times 2 \mathrm{~mm}$ were prepared. The specimens were divided into two groups according to the light-curing tips from a halogen light curing unit (Optilight Plus -GNATUS $/ 300 \mathrm{~mW} \cdot \mathrm{cm}^{-2}$ ): GI - optical fiber light-curing; GII - polymer light-curing. After 24 hours, the microhardness measurements were determined using the HMV 2000 (Shimadzu Japan). Five measurements were made on each surface (top and bottom) totalizing 10 indentations for each sample. Statistical analysis using ANOVA showed no significant differences between the light-curing tips on both surfaces evaluated. It was found a statistically significant difference between the top and bottom for both light-curing tips. Based on these results, we concluded that the light-curing tips did not affect the microhardness of the composite resin, and both showed statistically significant differences in microhardness for the top and bottom surfaces.
\end{abstract}

Keywords: Composite resin, microhardness and light curing.

\section{Introdução}

As resinas compostas são materiais estéticos que vem ganhando grande aplicabilidade na Odontologia atual, tanto nas restaurações de dentes anteriores como posteriores como afirma Franco e Lopes ${ }^{[6]}$. A longevidade clínica dessas restaurações está vinculada de maneira indelével com a adoção de uma adequada fotoativação $0^{[8]}$.

O processo de fotoativação dos materiais resinosos tem início quando a luz azul incide no agente fotossensível (fotoiniciador), geralmente a canforoquinona, que absorve luz no espectro visível com absorção máxima em $468 \mathrm{~nm}$. Após a absorção desta energia, a canforoquinona entra em estado excitatório tornando-se apta para reagir com uma amina terciária formando radical livres e o processo de polimerização é então desencadeado ${ }^{[14]}$. Para promover o inicio dessa reação, estão disponíveis no mercado diferentes fontes de luz, como: lâmpada halógena, laser de argônio, luz de arco de plasma e diodos emissores de luz (LEDs). Apesar das opções, os aparelhos de luz de lâmpada halógena ainda são os mais utilizados ${ }^{[10]}$.

A luz azul que desencadeia todo esse processo de fotoativação é exteriorizada do aparelho fotoativador por meio de ponteiras condutoras de luz que podem ser de fibra óptica ou de polímero ${ }^{[24]}$. As ponteiras de fibra óptica evitam a dispersão da luz conferindo apropriada fotoativação dos materiais resinosos. Já as ponteiras de polímero que foram recentemente introduzidas no mercado Odontológico apresentam vantagens com relação ao custo e a versatilidade de uso $^{[8,18]}$.

A ponteira condutora de luz de polímero pode alterar a propagação de luz quando em contato com impurezas. Tal característica pode ser compreendida pela forma de como a luz é transmitida através do meio. A luz que penetra no polímero é refratada em um ângulo proporcional entre a razão do índice de refração do ar e do meio de transmissão (polímero) ${ }^{[18]}$. A luz se propaga no interior do plástico até a superfície externa, sendo refratada para o interior do material em contato com o polímero. Caso alguma superfície, como lábios e bochechas, entre em contato com a ponteira de polímero, ocorrerá à diminuição da energia luminosa que se transmitiria até a resina composta com posterior prejuízo de suas propriedades físicas e mecânicas. Em algumas situações clínicas, isso representa uma grande desvantagem, uma vez que o contato com a ponteira de polímero com lábios, bochecha ou dique de borracha pode ocorrer inadvertidamente ${ }^{[1,17,18]}$. Na literatura científica atual poucos trabalhos avaliaram a eficácia de ponteiras de polímero acoplada a aparelho de lâmpada halógena na fotopolimerização de compósitos odontológicos quando comparado as ponteiras de fibra óptica ${ }^{[16,18]}$. 
Dessa forma, o presente estudo tem como objetivo avaliar a influência da fotoativação de uma resina composta por um aparelho de lâmpada halógena acoplado a diferentes ponteiras condutoras de luz (fibra óptica e de polímero) por meio de ensaio de resistência a penetração (microdureza Knoop).

\section{Materiais e Métodos}

\section{Confecção dos corpos de prova}

Neste estudo foi utilizada uma resina composta micro-híbrida na cor DA2 Opallis (FGM). Constituída por ingredientes ativos: monômeros de Bis-GMA (Bis-Fenol A di-Glicidil Metacrilato), BisEMA(Bis-Fenol Adi-Glicidil Metacrilato etoxilado), TEGDMA (Trietileno glicol dimetacrilato), UDMA (Uretano dimetacrilato), canforquinona, co-iniciador e silano. E por ingredientes inativos que são: vidro de bário-alumino silicato silanizado, pigmentos e sílicas. Os corpos de prova foram confeccionados em matriz elastômérica com orifício central de $5 \mathrm{~mm}$ de diâmetro e $2 \mathrm{~mm}$ de espessura. A resina composta foi inserida na matriz elastômero (Aquasil Ultra/Dentsply) em repouso sobre uma placa de vidro, num incremento único sendo preenchida totalmente com o auxílio de uma espátula Thompson (Prisma) (Figura 1). Após o preenchimento da matriz, foi colocada sobre a mesma uma tira de poliéster (Probem Ltda.) e sobre esta uma placa de vidro com $2 \mathrm{~mm}$ de espessura, realizando pressão de forma a conseguir uma superfície lisa. Em seguida, a placa de vidro foi removida da parte superficial, e realizada a fotoativação por 40 segundos com a ponteira em contato direto com tira de poliéster. Foi empregado aparelho de lâmpada halógena (Optilight Plus - Gnatus) com densidade de potência de $300 \mathrm{~mW} \cdot \mathrm{cm}^{-2}$, aferida em um radiômetro digital (Demetron). Os grupos foram divididos de acordo com a ponteira de luz empregada: Grupo I- ponteira condutora de luz de polímero (área retangular com $25 \times 13 \mathrm{~mm}$ e 8,3 cm de comprimento/Gnatus) (Figura 2); Grupo II- ponteira condutora de luz de fibra óptica (área com $8 \mathrm{~mm}$ de diâmetro e $8,3 \mathrm{~cm}$ de comprimento/Gnatus) (Figura 3). Ambas as ponteiras estavam emitindo $300 \mathrm{~mW} . \mathrm{cm}^{-2}$ no momento da fotoativação. Após a fotoativação, cada corpo de prova foi removido com auxílio de uma espátula metálica. Para a identificação da superfície de topo esta foi demarcada com uma ponta diamantada 1012 (KG SORENSEN).

Com base na variabilidade do fenômeno estudado e em estudos anteriores ${ }^{[16,18]}$, foram confeccionados 7 corpos de prova para cada tipo de ponteira de luz acoplada no aparelho fotoativador. As amostras foram devidamente identificadas e mantidas em recipiente fechado de material opaco com água deionizada. Os corpos de prova foram armazenados por 24 horas em estufa a $37^{\circ} \mathrm{C}$.

\section{Ensaio de resistência a penetração (dureza Knoop)}

Após 24 horas da confecção dos corpos de prova, os mesmos foram fixados em cera utilidade e submetidos ao teste de resistência a penetração microdureza Knoop. As medidas de microdureza foram efetuadas com microdurômetro HMV 2000 (Shimadzu), sob carga de 50 gramas por 15 segundos. Cinco penetrações foram efetuadas em cada superfície (topo e base) totalizando 10 penetrações para cada corpo de prova (Figura 4). Os valores obtidos em micrometros foram convertidos em número de microdureza Knoop. Os 140 dados obtidos referentes às medidas de microdureza foram analisados por meio de Análise de Variância (ANOVA) de dois critérios, com nível de significância de 5\%, e posteriormente foi utilizado o teste de comparações múltiplas Tukey HSD, através do programa BioEstat 5.0.

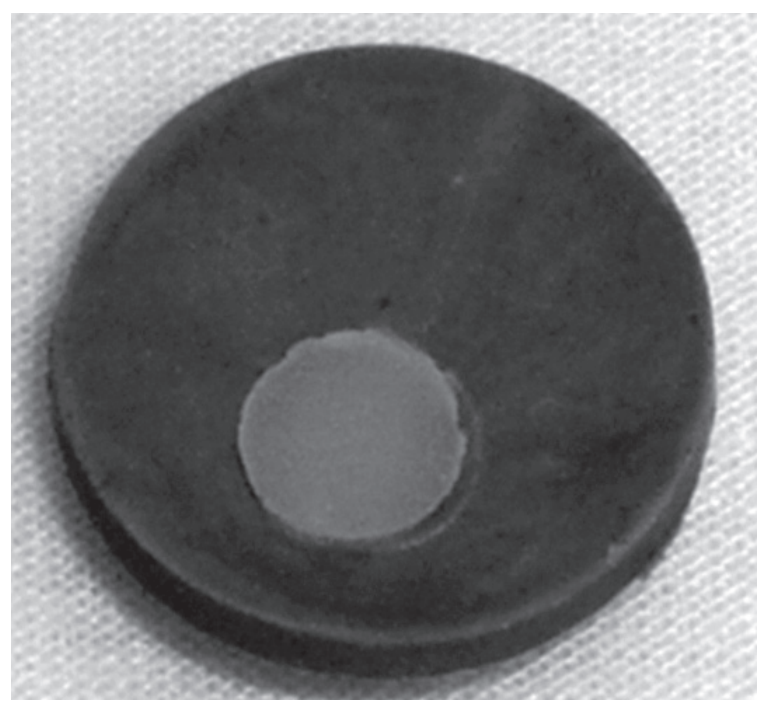

Figura 1. Matriz de elastômero e corpo de prova.

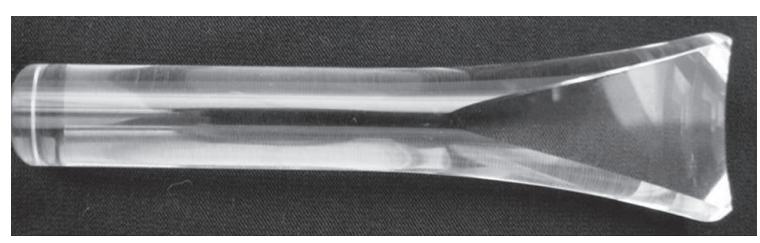

Figura 2. Ponteira condutora de luz de polímero.

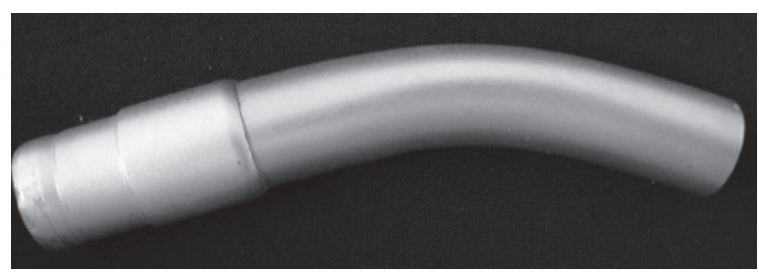

Figura 3. Ponteira condutora de luz de fibra óptica.

\section{Resultados}

A análise estatística demonstrou diferença estatisticamente significante nos valores médios de microdureza superficial entre as superfícies de topo e de base, para ambas as ponteiras avaliadas. Já a comparação entre o desempenho das ponteiras de fibra óptica e de polímero para a mesma superfície não apresentaram diferenças estatisticamente significantes.

A Tabela 1 e a Figura 5 descrevem os resultados da resina composta Opallis (FGM), quando submetido à fotoativação por um aparelho fotoativador de lâmpada halógena com os diferentes tipos de ponteiras condutoras de luz.

\section{Discussão}

Os materiais restauradores estéticos representam uma classe de materiais extensivamente utilizados na Odontologia. Embora apresentem estética satisfatória, suas propriedades físicas e mecânicas estão diretamente relacionadas à efetividade do procedimento de fotoativação ${ }^{[4]}$. Nesse sentido, os aparelhos de luz utilizados para ativar as resinas compostas devem cumprir alguns requisitos para realizar uma adequada fotoativação $0^{[1,10,12]}$. A luz que chega até a superfície da resina composta deve ser suficiente para uma apropriada absorção do fotoiniciador, sendo também de fundamental importância corretos comprimentos de onda e tempos exposição da luz ${ }^{[16]}$. Caso contrário, pode causar baixos níveis nas 


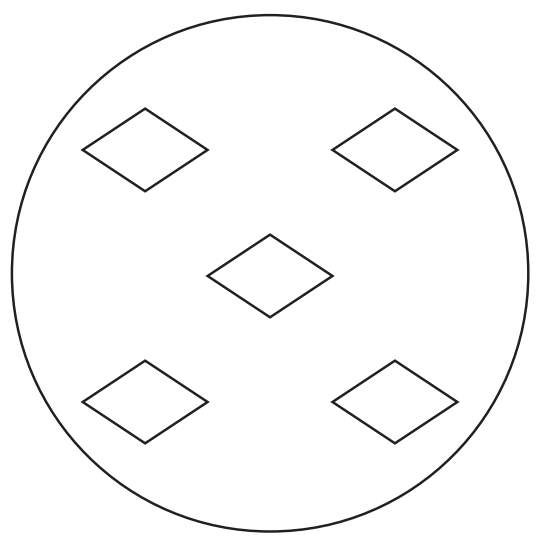

Figura 4. Desenho esquemático das cinco indentações.

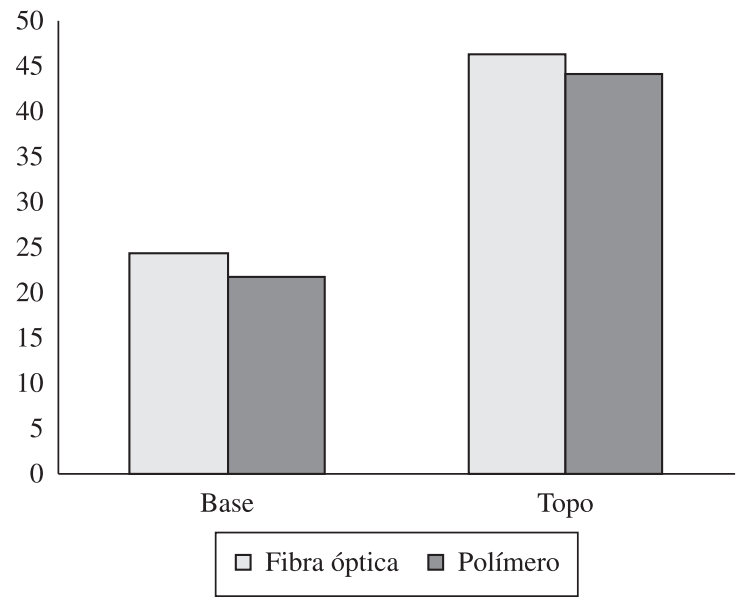

Figura 5. Valores de microdureza superficial para os grupos experimentais (Knoop).

Tabela 1. Valores médios de microdureza Knoop (KHN).

\begin{tabular}{ccc}
\hline & Fibra óptica & Polímero \\
\hline Base & $24,25( \pm 3,21) \mathrm{Aa}$ & $21,80( \pm 7,58) \mathrm{Aa}$ \\
Topo & $46,36( \pm 5,20) \mathrm{Ba}$ & $44,17( \pm 8,22) \mathrm{Ba}$ \\
\hline
\end{tabular}

$\mathrm{Na}$ análise entre colunas letras minúsculas diferentes representam diferenças estatisticamente significantes $(\mathrm{p}<0,05)$. Na análise entre linhas letras minúsculas diferentes representam diferenças estatisticamente significantes $(\mathrm{p}<0,05)$.

propriedades físicas desses materiais, como alta solubilidade, falhas na retenção, infiltração marginal e sensibilidade pós-operatória pela presença de monômeros residuais não fotoativados ${ }^{[21]}$. A profundidade de fotoativação pode ser influenciada por fatores como tipo de ponteira, intensidade de luz, tempo de fotoativação e comprimento de onda ${ }^{[13]}$

As ponteiras condutoras de luz mais utilizadas nos aparelhos de lâmpada halógena são as de fibra óptica ${ }^{[24]}$. O uso das ponteiras condutoras de luz de polímero foi proposto como uma alternativa de menor custo, mas suas propriedades de transmissão poderiam ser afetadas pelo aquecimento gerado pelos aparelhos de lâmpada halógena ${ }^{[9]}$. Contudo, Rueggeberg e Caughman ${ }^{[18]}$ demonstraram que esse tipo de ponteira de luz não se altera quando utilizadas durante 6 minutos nos aparelhos de lâmpada halógena.

Os testes de microdureza têm sido utilizados em vários estudos como um método viável para avaliar a relativa profundidade de polimerização das resinas compostas e conseqüentemente a eficiência da fonte de luz ${ }^{[5,11,2,23]}$. Portanto, neste estudo, a microdureza foi usada como um mensurador indireto da profundidade de polimerização da resina composta utilizada.
Na presente pesquisa não foi identificado diferenças estatísticas significantes nos valores de microdureza Knoop para os grupos com ponteiras condutoras de luz de fibra óptica e de polímero tanto na superfície de topo (polímero $44,17(+8,22)$ e fibra óptica $46,36(+5,20))$ como na de base (polímero 21,80 (+7,58) e fibra óptica 24,25 $(+3,21)$ ). Resultados semelhantes foram encontrados por Giorgi, Dias e Paulillo ${ }^{[7]}$ que não encontraram diferenças na microdureza superficial de uma resina composta fotoativada com aparelho de luz LED com ponteira de polímero ou de fibra óptica. Soares, Liporini e Martins ${ }^{[22]}$ relataram que o tipo de material da ponteira condutora de luz também não interfere no grau de conversão de resina compostas micro-híbridas.

Resultados diferentes foram encontrados por Cchuana-Vasquez et al. ${ }^{[1]}$ onde as ponteiras de polímero apresentaram os melhores resultados no teste microdureza em comparação com as de fibra óptica. Tal diferença dos resultados com relação aos dados obtidos do presente estudo pode ser explicada pelo fato dos autores terem utilizados aparelhos de luz LEDs que possuem menor densidade de potência e emissão de calor.

Rueggeberg and Caughman ${ }^{[18]}$ confrontaram ponteira condutora de luz de polímeros e de fibra óptica em aparelhos de lâmpada halógena quanto aos fatores que poderiam afetar a transmissão de luz e na microdureza superficial. Os resultados demonstraram que a intensidade de luz foi dependente da marca da ponteira de polímero utilizada e dos aparelhos testados. E que as ponteiras de polímero são tão efetivas quanto às de fibra óptica, o que vem ao encontro dos resultados encontrados na presente pesquisa. Verificaram também que a presença de algumas impurezas ou imperfeições no interior da ponteira de polímero pode afetar a transmissão de luz.

As ponteiras condutoras de luz utilizadas no presente estudo, além de serem constituídas por distintos materiais também apresentavam dimensões diferentes, quando comparado a estudos anteriores ${ }^{[7,18]}$. Foram selecionadas para o estudo por serem produzidas pelo mesmo fabricante do aparelho de luz. Tais dimensões da ponteira condutora de luz podem interferir na qualidade da luz emitida ${ }^{[17]}$. O diâmetro padrão é de $8 \mathrm{~mm}$ em todo o seu comprimento, estando às paredes paralelas entre si. Já para as ponteiras com dimensões maiores esse paralelismo não ocorre. A extremidade a ponteira torna-se mais ampla e as paredes divergentes aumentam a efetividade da irradiação ${ }^{[15]}$. Contudo, Vandewalle, Roberts e Rueggeberg ${ }^{[24]}$ encontraram que tais ponteiras são tão efetivas na distribuição da luz quanto às ponteiras padrão. E no teste de microdureza ambas apresentaram valores estatisticamente semelhantes entre si, o que corrobora com os resultados encontrados na presente pesquisa.

Foram encontradas diferenças quanto ao valor de microdureza Knoop entre as superfícies de topo e base dos corpos de prova para ambas as ponteiras condutoras de luz avaliadas. Esse resultado é contrário ao de outros trabalhos que afirmam que qualquer resina composta quando exposta a luz fotoativadora com comprimento de onda de $468 \mathrm{~nm}$ é capaz de polimerizar adequadamente incrementos de $2 \mathrm{~mm}^{[3]}$, o que não foi observado. As diferenças encontradas corroboram com estudos que relatam um decréscimo na polimerização de resinas compostas com $2 \mathrm{~mm}$ de espessura, sendo $1,0 \mathrm{~mm}$ o ideal para uma polimerização satisfatória ${ }^{[17,19]}$.

As características do aparelho fotoativador podem ter influenciado nos baixos valores de microdureza nas superfícies de base dos corpos de prova. Rueggeberg et al. ${ }^{[17]}$, recomendam que uma densidade de potência mínima de $233 \mathrm{~mW} . \mathrm{cm}^{-2}$ seja utilizada para uma adequada polimerização com tempo de 40 segundos. Justificando a utilização no presente trabalho de um aparelho de lâmpada halógena com $300 \mathrm{~mW} \cdot \mathrm{cm}^{-2}$. Contudo, Santos et al. ${ }^{[2]}$ verificaram que os melhores resultados de microdureza foram encontrados para os aparelhos de lâmpada halógena com densidade de potência acima de $400 \mathrm{~mW} \cdot \mathrm{cm}^{-2}$ para o tempo de 40 segundos de exposição. 
O processo fotoativação de resinas compostas é bastante complexo e envolve vários fatores. Apesar das diferentes ponteiras não interferirem nos valores de microdureza, outros cuidados devem ser levados em conta como as características do aparelho fotoativador, tais como comprimento de onda, densidade de potência, presença ou não de filtros, tempo de vida útil do aparelho, tipo de manutenção e suas vantagens e desvantagens ${ }^{[17]}$.

Os resultados do presente estudo demonstraram que não houve diferença estatística para os valores de microdureza entre os tipos de ponteiras de luz testadas, entretanto, observou-se a presença de diferenças estatisticamente significantes entre as superfícies de base e de topo testadas, com redução de aproximadamente $50 \%$ dos valores de microdureza obtidos. Tal situação quando transportada para a prática clínica do cirurgião-dentista, pode trazer sérios problemas pós-operatórios aos pacientes como infiltração marginal, sensibilidade, falhas na retenção e diminuição da vida útil dessas restaurações. Assim, alguns cuidados devem ser tomados pelo profissional durante o procedimento restaurador como: espessura do incremento de resina composta, tempo de exposição a luz, densidade de potência do aparelho e resina composta selecionada, independente do tipo de ponteira utilizado. Além disso, estudos clínicos deveriam ser realizados para comprovar a efetividade dessas ponteiras na longevidade das restaurações.

\section{Conclusão}

Com base nos resultados obtidos pode-se concluir que não há superioridade entre as ponteiras condutoras de luz de fibra óptica e de polímero estudados quanto aos valores de microdureza da resina composta. Porém, ambas as ponteira avaliadas apresentaram diferenças estatisticamente significativas entre as superfícies de topo e base.

\section{Referências Bibliográficas}

1. Ccahuana-Vásquez, R. A.; Torres, C. R. G.; Araújo M. A. M. \& Anido A. - Rev. Fac. Odontol. Araraquara. Ciênc. Odontol. Bras., 33, p.69-73 (2004).

2. Cefaly, D. F.; Ferrarezi, G. A.; Tapety, C. M.; Lauris, J. R. \& Navarro, M. F. - Braz. Dent. J., 16, p.98-102 (2005).

3. Carreia A. J. \& Vieira, D. - Ver. JADA-Brasil., 5, p.58-63 (2002).

4. David, J. R.; Gomes, O. M.; Gomes, J. C.; Loguercio, A. D. \& Reis, A. - J. Oral. Sci., 49, p.19-24 (2007).
5. Dunn, W. \& Bush, A. C. - J. Am. Dent. Assoc., 133, p.335-41 (2002).

6. Franco, E. B. \& Lopes, L. G. Rev. Biodont., 1, p.09-59 (2003).

7. Giorgi, M. C. C.; Dias, C. T. S. \& Paulillo, L. A. M. S. - Ciênc. Odontol. Bras., 11, p.8-23 (2008).

8. Hansen, E. K. \& Asmussen, E. - J. Dent. Res., 10, p.176-79 (1993).

9. Knezević, A.; Tarle, Z.; Meniga, A.; Sutalo, J.; Pichler, G. \& Ristić, M. - J. Oral. Rehabil., 6, p.586-91 (2001).

10. Krämer, N.; Lohbauer, U.; García-Godoy, F. \& Frankenberger, R. Am. J. Dent., 21, p.135 (2008).

11. Kurachi, C.; Tuboy, A. M.; Magalhães, D. V. \& Bagnato, V. S. - Dent. Mater., 17, p.309 (2001).

12. Lopes, L. G. \& Martin, E. - ROBRAC, 15, p.19 (2006).

13. Martin, F. E. \& Lopes, L. G. - J. Dent., 26, p.239-43 (1998).

14. Park, S. H.; Chae, K. H. \& Ralws, H. R. - Dent. Mater., 15, p.120 (1999).

15. Price, R. B.; Dérand, T.; Sedarous, M.; Andreou, P. \& Loney, R. W. - J. Esthet. Dent., 12, p.320 (2000).

16. Rueggeberg, F. A.; Ergle, J. W. \& Mettenburg, D. J. - J. Esthet. Dent., 12, p.340-9 (2000).

17. Rueggeberg, F. A.; Caughman, W. F.; Curtis Jr., J.,W. \& Davis, H. C. Oper. Dent., 19, p.26 (1994).

18. Rueggeberg, F. A. \& Caughman, W. F. - Oper. Dent., 4, p.179 (1998).

19. Sakaguchi R. L. \& Berge H. X. Reduced light energy density decreases post-gel contraction while maintaining degree of conversion in composites. J Dent., 26, p.695-700 (1998).

20. Santos, L. A.; Turbino, M. L.; Youssef, M. N. \& Matson, E. - Braz. Oral Res., 14, p.65 (2000).

21. Silva, E. V.; Araújo, P. A. \& Francisconi, P. A. S. - Rev. Fac. Odontol. Bauru., 10, p.7 (2002).

22. Soares L. E.; Liporoni, P. C. \& Martin, A. A. - Oper. Dent., 32, p.155-60 (2007).

23. Ulhoa, M. P. M.; Santana, L. R. S.; Bianchi, E. C.; Cruz, C. E. D.; Aguiar, P. R.; Freitas, C. A. \& Freitas, M. F. A. - Polímeros, 17, p.258 (2007).

24. Vandewalle, K. S.; Roberts, H. W. \& Rueggeberg, F. A. - J. Esthet. Restor. Dent., 20, p.108 (2008).

Enviado: 10/03/10

Reenviado: $19 / 05 / 10$

Aceito: $20 / 05 / 10$

DOI: $10.1590 /$ S0104-14282010005000057 